\title{
Influence of machining parameters on surface roughness in WEDM cutting
}

\author{
Sergiu Lazăr ${ }^{1}$ \\ ${ }^{1}$ Faculty of Engineering, Lucian Blaga University of Sibiu, Sibiu, Romania \\ E-mail: sergiu.lazar@ulbsibiu.ro
}

\begin{abstract}
Wire Electrical Discharge Machining is a cutting method used for obtaining parts with complex geometries or for cutting hard metals. This paper seeks to emphasize the importance of this unconventional technology and more specifically the importance of knowing the parameters of a process before planning the production of a benchmark. Cylindrical metal carbide parts with a hardness of $1620 \mathrm{HV} / 92 \mathrm{HRC}$ were cut during the analysis9, using the minimum and maximum values of the cutting parameters: wire feed rate, wire rotation speed, wire tension, dielectric pressure, electrical current(A) and electrical potential (V). The roughness of the obtained surfaces has been measured after being cut and a comparison table that includes the parameters values set by the user and the measured roughness was drawn up.
\end{abstract}

Keywords: WEDM, surface roughness, cutting parameters, machining.

\section{Introduction}

Electrical Discharge Machining process was discovered by two Russian scientists R. Lazarenko and I. Lazarenko in 1943 and in the beginning, it was used only in the military industry. This subtractive machining process is used to machine especially very hard metals like pre-hardened steel or Titanium, but it can also be used for other materials which are electro conductive. Sometimes EDM is used to make objects like mold cavities because it is impossible to obtain a complex geometry using traditional cutting processes. [1]

The evolution of technology in the last two decades has put pressure on the development of unconventional technologies, especially micro technologies. Although the unconventional technologies like wire electrical discharge machining were extensively studied, no revealed aspects are known regarding the cutting parameters influence the workpiece. [2]

\section{Basic information of EDM process}

The main concept behind WEDM is about the way of an electric arc can erode the surface of a material. These electric arcs form when the voltage difference between two closely separated objects, called electrodes, becomes large enough to overcome the resistance of the gap between them. When this occurs, a current of up to 500 A flows through a microscopically small area, vaporizing the surface of the electrodes. This vaporization separates some material from the larger workpiece, leaving a pit on the surface. As numerous arcs occur, this pitting erodes the surface over a large area, shaping it in the desired manner. [3]

WEDM is based on complex, discontinuous and localized erosive effects of repetitive pulsed electric discharges between the workpiece and the electrode. As mentioned earlier, only materials that have electrical conductivity can be processed. [4] 
Volume 2, Issue 2, 2020

ISSN: 2668-0416

Thoth Publishing House

\section{Experimental procedure}

Experimental trials are performed by cutting $\varnothing 18.8 \mathrm{~mm}$ metal carbide bars. A metallographic analysis was performed to determine the elemental structure of the material, Figure 1. A Leika DM6 M LIBS metallographic microscope was used.

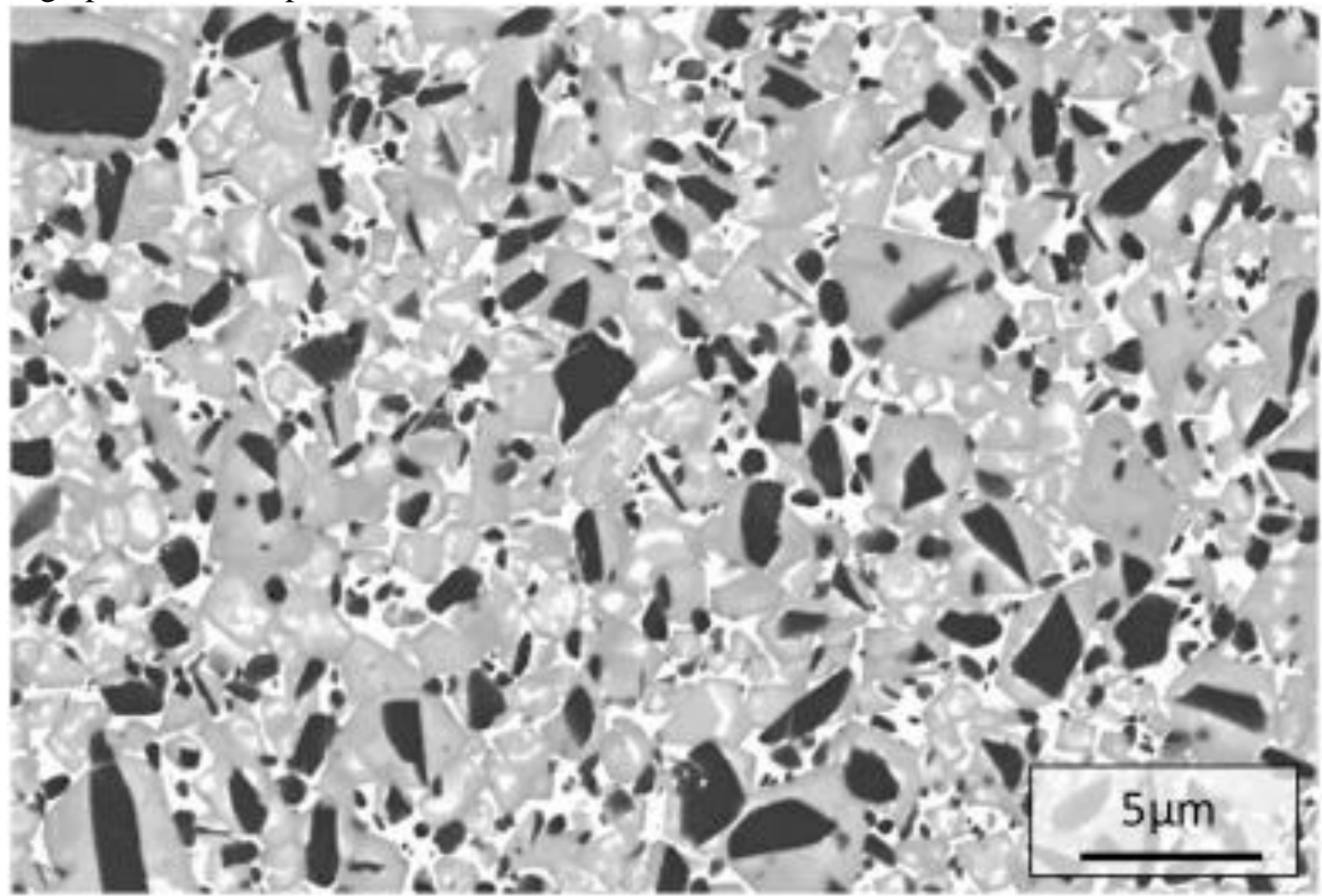

Figure 1. Metallographic analysis for carbide bar

Metal carbide contains $10 \%$ Cobalt $(\mathrm{Co})$ and the size of the Tungsten $(\mathrm{W})$ grains reaches a maximum of $0.5 \mu \mathrm{m}$. There is also Carbon (C) with black, Titanium (Ti) and Tantalum (Ta). After analysing the elemental structure, the hardness of the carbide bars was analysed. For this, the Vickers method was used on a Struers Duramin 40 durometer, Table 1. The square-shaped frame with a square base and a diamond tip was applied for 18 seconds, according to ISO6507. The hardness of the outer cylindrical surface was measured. In Table 2 . the values obtained from the hardness test analysis can be found.

Table 1. Hardness test results

\begin{tabular}{|c|c|c|c|c|c|c|c|c|c|c|}
\hline Sample nr. & $\mathbf{1}$ & $\mathbf{2}$ & $\mathbf{3}$ & $\mathbf{4}$ & $\mathbf{5}$ & $\mathbf{6}$ & $\mathbf{7}$ & $\mathbf{8}$ & $\mathbf{9}$ & $\mathbf{1 0}$ \\
\hline Hardness [HV] & 1620 & 1618 & 1618 & 1620 & 1620 & 1620 & 1619 & 1620 & 1620 & 1620 \\
\hline
\end{tabular}

Metal carbide bars will be machined on the AgieCharmilles AC Progress V4. The cutting was made with CobraCut A wire of size $\varnothing 0.25 \mathrm{~mm}$, made of CuZn36 material (brass). During machining, the maximum spark size is $0.06 \mathrm{~mm}$. The tensile strength the wire is $900 " \mathrm{~N} / \mathrm{mm} 2 "$. 
The dielectric used for WEDM is a combination of water with cationic resin SurTec476, maintained at a temperature of $18.8 \ldots 19.2{ }^{\circ} \mathrm{C}$. The role of the dielectric is to cancel the electrical conductivity of the water, to cool the spark electrode and to wash the microparticles.

The next step of the study was to determine the parameters that can be changed on the machine mentioned above. In the table below are the parameters that could be modified by the user in correlation with their minimum and maximum values.

Table 2. The minimum and maximum values of the parameters on the WEDM machine

\begin{tabular}{|c|c|c|}
\hline \multirow{2}{*}{ Parameter } & \multicolumn{2}{|c|}{ Values } \\
\cline { 2 - 3 } & min. & max. \\
\hline Wire feed rate $[\mathrm{mm} / \mathrm{min}]-\mathbf{V}_{\mathbf{a}}$ & 0,50 & 4 \\
\hline Wire rotation speed [mm/min] $-\mathbf{V}_{\mathbf{r}}$ & 90 & 325 \\
\hline Dielectric pressure [mmHg] - $\mathbf{P}_{\mathbf{d}}$ & 0,30 & 18 \\
\hline Wire tension [N] - $\mathbf{T}_{\mathbf{f}}$ & 10 & 40 \\
\hline Electrical current [A] $\mathbf{I}$ & 1 & 40 \\
\hline Electrical potential [V] - U & 12 & 82 \\
\hline
\end{tabular}

The cutting parameters found in the table above are: $V_{a}$ - wire feed rate, $V_{r}$ - wire rotation speed, $T_{f}$ - wire tension, $\mathrm{P}_{\mathrm{d}}$ - dielectric pressure, I - electrical current(A) and $\mathrm{U}$ - electrical potential (V). Considering that the user can change a number of six parameters, with two values (minimum and maximum), it will be determined the total number of parts that must be made to have a complete study:

$$
2^{6}=64-\text { number of cutting parts }
$$

In this phase of the study, it was decided to perform 6 cuts and making only 6 workpieces to find the preliminary data for establishing a mathematical calculation model. Subsequently, to validate the mathematical model will be done another 58 workpieces with the other parameters. The main reason why we chose to cut only 6 pieces is the ease of establishing a model of influence of the parameters on the surface roughness.

The roughness of the cut parts was measured using a Mitutoyo Surftest SJ-301 roughness meter. A linear surface was measured at mid-height, more precisely at half the diameter, as can be seen in Figure 2 .

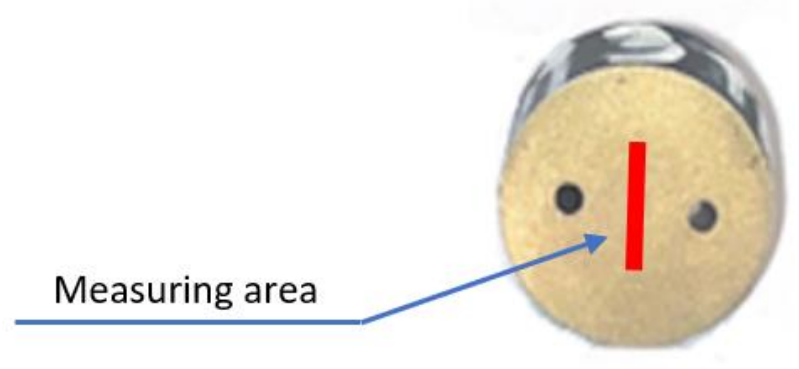

Figure 2. Roughness measuring area

Regarding the roughness measurement, the arithmetical mean deviation of the assessed profile Ra, the maximum height of the profile $\mathrm{Rz}$ and maximum peak height $\mathrm{Rp}$ were measured. [5]. The values of the test parameters and the resulting roughness is shows in Table 3. 
Table 3. The values of the test parameters and the resulting roughness

\begin{tabular}{|c|c|c|c|c|c|c|c|c|c|}
\hline $\mathbf{N r}$. & $\begin{array}{c}\text { Wire feed } \\
\text { rate } \\
{[\mathbf{m m} / \mathbf{m i n}]}\end{array}$ & $\begin{array}{c}\text { Wire } \\
\text { rotation } \\
\mathbf{s p e e d} \\
{[\mathbf{m m} / \mathbf{m i n}]}\end{array}$ & $\begin{array}{c}\text { Dielectric } \\
\mathbf{p r e s s u r e} \\
{[\mathbf{m m H g}]}\end{array}$ & $\begin{array}{c}\text { Wire } \\
\text { tension } \\
{[\mathbf{N}]}\end{array}$ & $\begin{array}{c}\text { Electrical } \\
\text { current } \\
{[\mathbf{A}]}\end{array}$ & $\begin{array}{c}\text { Electrical } \\
\mathbf{p o t e n t i a l} \\
{[\mathbf{V}]}\end{array}$ & $\begin{array}{c}\mathbf{R}_{\mathbf{a}} \\
{[\boldsymbol{\mu \mathbf { m } ]}]}\end{array}$ & $\begin{array}{c}\mathbf{R}_{\mathbf{z}} \\
{[\boldsymbol{\mu} \mathbf{m}]}\end{array}$ & $\begin{array}{c}\mathbf{R}_{\mathbf{a}} \\
{[\boldsymbol{\mu \mathbf { m } ]}]}\end{array}$ \\
\hline 1 & 0.5 & 325 & 18 & 40 & 1 & 82 & $\mathbf{0 , 0 8}$ & 0,92 & 0,12 \\
\hline 2 & 4 & 90 & 0.3 & 10 & 40 & 12 & $\mathbf{2 , 9 0}$ & 16,12 & 3,55 \\
\hline 3 & 2.8 & 310 & 16 & 35 & 14 & 80 & 1,16 & 6,88 & 1,41 \\
\hline 4 & 1 & 300 & 15 & 20 & 10 & 60 & 0,70 & 5,21 & 0,87 \\
\hline 5 & 1.5 & 305 & 13.5 & 27 & 3 & 75 & 0,33 & 2,29 & 0,42 \\
\hline 6 & 1.1 & 267 & 12 & 30 & 2.5 & 30 & 0,27 & 1,87 & 0,34 \\
\hline
\end{tabular}

The veracity of the values presented above can be extracted from the measurement reports of the Mitutoyo Surftest microscope, which can be found below, in Figure 3.

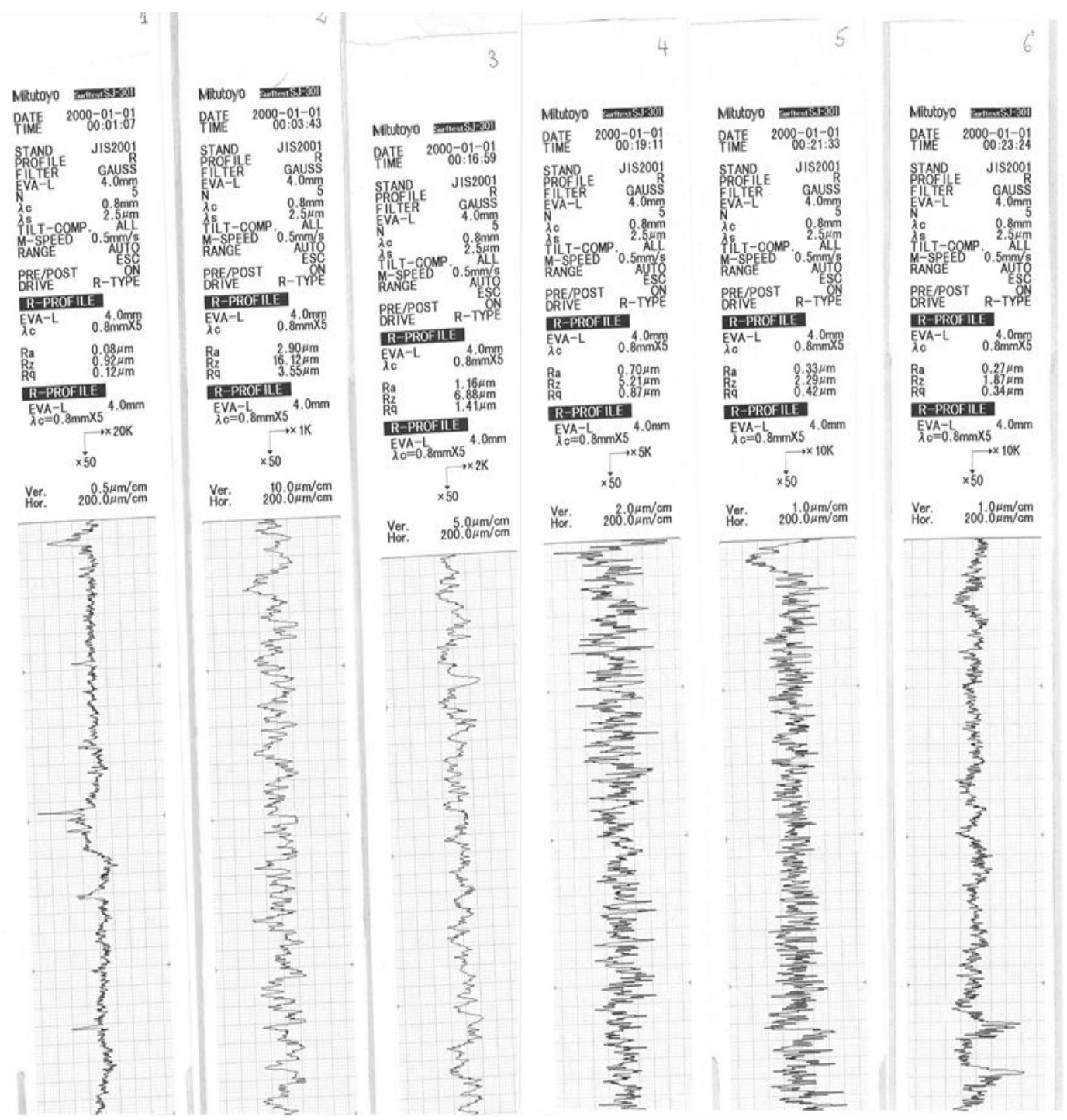

Figure 3. Roughness measurement reports 
The purpose of this study is close to fulfilment. As can be seen, the most important parameter influencing the roughness of the surface is the wire feed rate: the higher the value of the wire feed rate, the higher the surface roughness. This is justified by the fact that during cutting the surfaces are processed very little due to the high speed of movement of the wire. Consequently, the wire fails to ensure their complete finishing. [6]

The second important factor that influences the quality of surfaces is the electric current. The highest roughness Ra was obtained where the electric current has the highest value. This is explained by the fact that the size of the spark is difficult to control and erodes a larger amount of material.

The roughness decreases only when the value of the parameter $U, P_{d}$ and $T_{f}$ have high values. Of these parameters that decrease the value of roughness, the most significant seems to be the electric potential. [7]

Even if the low roughness values can only be observed with the help of special tools, in Fig. 4. a significant difference of the pieces obtained due to the pattern can be observed.
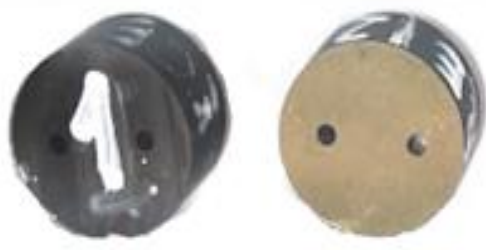
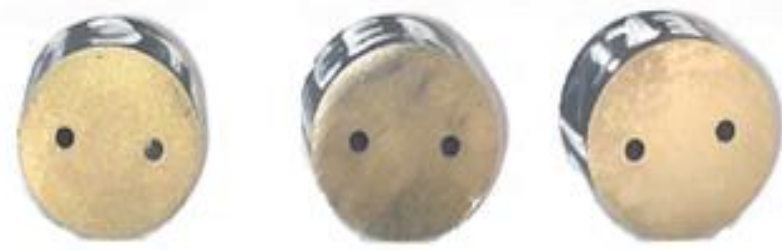

Figure 4. Parts cut by EDM

\section{Conclusions}

For the industry it would be important to prepare a library with specified parameters for machining different materials. For example, for the same kind of machining (roughing or finishing), in the tables of the machine-tools, the parameters are optimized but it is not specified the quality of the surface that can be obtained. Also, a mathematical model will improve the knowledge of the phenomena and it will open the possibilities of using the process in different applications. This is the next step of this study. [1]

Although it is very important that the productivity of this process is high, i.e. the parameter $\mathrm{V}_{\mathrm{a}}$ has maximum values during processing, it must be considered that the principle of the quality of the parts matters first.

Thus, the most important thing in WEDM machining is to establish the optimal parameters that consider productivity and quality. It is unlikely that maximum productivity and maximum quality can be achieved.

\section{Bibliography}

[1] P. Marcel Sabin, C. Glad, P. Grigore, „Surface quality of the EDM processed materials, ” in XIX IMEKO World Congress Fundamental and Applied Metrology, Lisbon, 2009.

[2] C. M. Simion, Studies and research on the surface roughness processed by EDM - PhD Thesis, București: Politehnica Publishing House, 1999.

[3] N. Hesse, „Pen State Site,” Penn State, 04 2016. [Interactiv]. Available: http://sites.psu.edu/nwhesse/wp-content/uploads/sites/37237/2016/04/Definition-EDM.pdf.

[4] C. I. Deneș, Contributions regarding WEDM processing - PhD Thesis, Sibiu: "Lucian Blaga" University of Sibiu, 2002.

[5] D. Dobrotă, Basics of designing cutting processes, vol. I, Craiova: Sitech Publishing House, 2007, p. 272.

[6] A. Nanu și D. Nanu, Dimensional processing by EDM in magnetic field, Sibiu: Facla Publishing House, 1981.

[7] D. Nanu, Treaty of unconventional technologies. Vol.II: Processing by EDM, Sibiu: "Lucian Blaga" University of Sibiu Publishing House, 2004. 